\title{
Assessing the degree of plug flow in oxidation flow reactors (OFRs): a study on a potential aerosol mass (PAM) reactor
}

\author{
Dhruv Mitroo ${ }^{1, a, *}$, Yujian Sun ${ }^{1, *}$, Daniel P. Combest ${ }^{2}$, Purushottam Kumar ${ }^{3}$, and Brent J. Williams ${ }^{1}$ \\ ${ }^{1}$ Department of Energy, Environmental \& Chemical Engineering, Washington University in St. Louis, St. Louis, MO, USA \\ ${ }^{2}$ ENGYS LLC, St. Louis, MO, USA \\ ${ }^{3}$ Discipline of Chemical Engineering, Indian Institute of Technology Gandhinagar, Palaj, Gujarat 382355, India \\ ${ }^{a}$ now at: Department of Atmospheric Sciences, Rosenstiel School of Marine and Atmospheric Sciences, \\ University of Miami, Miami, FL, USA \\ *These authors contributed equally to this work.
}

Correspondence: Brent J. Williams (brentw@wustl.edu)

Received: 27 September 2017 - Discussion started: 29 November 2017

Revised: 23 February 2018 - Accepted: 27 February 2018 - Published: 27 March 2018

\begin{abstract}
Oxidation flow reactors (OFRs) have been developed to achieve high degrees of oxidant exposures over relatively short space times (defined as the ratio of reactor volume to the volumetric flow rate). While, due to their increased use, attention has been paid to their ability to replicate realistic tropospheric reactions by modeling the chemistry inside the reactor, there is a desire to customize flow patterns. This work demonstrates the importance of decoupling tracer signal of the reactor from that of the tubing when experimentally obtaining these flow patterns. We modeled the residence time distributions (RTDs) inside the Washington University Potential Aerosol Mass (WU-PAM) reactor, an OFR, for a simple set of configurations by applying the tankin-series (TIS) model, a one-parameter model, to a deconvolution algorithm. The value of the parameter, $N$, is close to unity for every case except one having the highest space time. Combined, the results suggest that volumetric flow rate affects mixing patterns more than use of our internals. We selected results from the simplest case, at $78 \mathrm{~s}$ space time with one inlet and one outlet, absent of baffles and spargers, and compared the experimental F curve to that of a computational fluid dynamics (CFD) simulation. The F curves, which represent the cumulative time spent in the reactor by flowing material, match reasonably well. We value that the use of a small aspect ratio reactor such as the WU-PAM reduces wall interactions; however sudden apertures introduce disturbances in the flow, and suggest applying the methodology of tracer testing described in this work to investigate RTDs in OFRs to
\end{abstract}

observe the effect of modified inlets, outlets and use of internals prior to application (e.g., field deployment vs. laboratory study).

\section{Introduction}

Tubular reactors were first introduced to the field of atmospheric science by means of small flow cell reactors developed to study the kinetics of stratospheric reactions (Brune et al., 1983; Howard, 1979; Keyser, 1980; Lamb et al., 1983). Accurate kinetic measurements were possible due to the high pipe aspect ratios, which encouraged a high degree of plug flow behavior (Keyser, 1984). The design of these miniature tubular reactors, with volumes on the order of a few $\mathrm{cm}^{3}$, was different from that of significantly larger, batch-type or semi-continuous type well-mixed reactors, with volumes on the order of several $\mathrm{m}^{3}$, built to understand aerosol formation in the troposphere (Crump et al., 1982; Crump and Seinfeld, 1980; Leone et al., 1985). To study aerosol formation and growth chemistry, the dynamics of atmospheric circulation and transport needed to be excluded. It was therefore convenient to mimic the troposphere by treating it as an enormous, well-mixed reactor, which led to the development of larger well-mixed reactors. The discovery of secondary processes preceding aerosol formation led to significant emphasis on the study of secondary organic aerosol (SOA) formation (Haagen-Smit, 1952, 1963, 1970; Went, 1960). The ap- 
proach of using large, well-mixed batch-style environmental chambers eventually helped elucidate chemical mechanisms for model compounds (Claeys, 2004; Kamens et al., 1982; Kroll et al., 2006; Nozière et al., 1999; Paulson et al., 1990; Pereira et al., 2015; Volkamer et al., 2001), and, with improved instrumentation (Canagaratna et al., 2007; Crounse et al., 2006; de Gouw and Warneke, 2007; Hansel et al., 1995; Jayne et al., 2000; Williams et al., 2006; Zhao et al., 2013), the community gained a better understanding of SOA formation. Unfortunately, low levels of conversion and high wall losses seen in these large reactors did not allow simulated exposures that exceeded a day at most, which is just a short glimpse into the average 2-week lifespan of an atmospheric aerosol (Seinfeld and Pandis, 2006). Due to such limitations, oxidation flow reactors (OFRs) with short spacetimes (ratio of reactor volume to the volumetric flow rate) are being developed (Cazorla and Brune, 2010; Ezell et al., 2010; George et al., 2007; Huang et al., 2017; Kang et al., 2007).

OFRs can be viewed as tubular reactors due to their pipe aspect. They have been widely used for over a decade to study heterogeneous reactions on organic aerosol surfaces involving gas-phase oxidants such as hydroxyl radicals and ozone (George et al., 2007; George and Abbatt, 2010; Katrib et al., 2005; Kessler et al., 2010, 2012; Knopf et al., 2005; Kroll et al., 2012; Smith et al., 2009). These reactors are able to generate very high concentrations of hydroxyl $(\mathrm{OH}) \mathrm{rad}-$ icals, tens to thousands of times higher than typical tropospheric levels, which accelerates the rate of gas-phase oxidation reactions. Within spacetimes of a few minutes, it is possible to achieve integrated oxidant exposures equivalent to multiple days or weeks of atmospheric oxidation. It is important to distinguish OFRs from modern-day conventional flow tube reactors, which stem from designs of old flow tube reactors (e.g., Keyser, 1984) but employed in the study of gas uptake kinetics on aerosol surfaces rather than homogeneous gas-phase reactions, as described in the previous paragraph. Beyond the original application of heterogeneous oxidation studies, Kang et al. $(2007,2011)$ introduced the potential aerosol mass (PAM) OFR which, alongside newer OFR designs, was intended specifically for studies of SOA physicochemical properties (Kang et al., 2007, 2011; Keller and Burtscher, 2012; Lambe et al., 2011b, 2012, 2013; Massoli et al., 2010; Ortega et al., 2013; Slowik et al., 2012). This application therefore altered the study of SOA formation, previously dominated by the traditional large, well-mixed reactors (Kroll and Seinfeld, 2008; Rudich et al., 2007; Turpin et al., 2000), by allowing the generation of laboratory data beyond first simulated day of exposure. Because the mechanism of exposure between traditional chambers OFRs was different, validating the OFR concept began by replicating data obtained from traditional chambers (Chhabra et al., 2015; Lambe et al., 2015; Liu et al., 2015), and assessing whether the chemistry was realistic (Li et al., 2015; McNeill et al., 2008; Peng et al., 2015; Renbaum and Smith, 2011). Consequently, much modeling work has focused on pure chemi- cal reactions and comparison of SOA yields between the two (Bruns et al., 2015; Lambe et al., 2015; Li et al., 2015; Ortega et al., 2016; Peng et al., 2015). However, little modeling work has been done on understanding hydrodynamics or flow fields inside OFRs so that the flow patterns can be improved. In a study from Li et al. (2015), it appears that residence time distributions (RTDs) that deviate significantly from plug flow in the PAM result only in an $\sim 10 \%$ error of reported values such as $\mathrm{OH}$ exposure ( $\mathrm{Li}$ et al., 2015), which is conducive to OFRs being viewed as tubular reactors. Following an experimentally determined RTD (Lambe et al., 2011) in a PAM OFR, Peng et al. extend the model developed by Li et al. (2015), to include this non-ideal RTD, suggesting model disagreement at high exposures. Ortega et al. (2016) employ FLUENT to show that removal of the inlet plate (resulting in a less pronounced aperture to the reactor) significantly decreases recirculation regions; Palm et al. (2017) then extend the simulation to show that the FLUENT-derived RTD (Palm et al., 2017) has a narrower distribution than the experimentally derived RTD by Lambe et al. Finally, Peng and Jimenez lay an initial framework for the possibility of OFRs investigating NO chemistry (Peng and Jimenez, 2017), where initial sensitivity analysis on RTDs suggest considerable model disagreement at high exposures. The fundamental caveat in this recent work is the reliance on an accurately determined experimental RTD that provides the basis for error analysis.

In both single and multiphase reactors, contact patterns and the degree of mixing determine reactor performance, e.g., selectivity and yield (Bourne, 2003; Deckwer, 1976; Levenspiel, 1999). This implies that upon desired contacting, chemical pathways that would be otherwise suppressed can become more competitive. For example, if during a mixed $\mathrm{OH} /$ ozonolysis heterogeneous reaction, a fresh biomass burning aerosol is introduced in the centerline port of an OFR and ozone is introduced along a side port, most of the aerosol may travel ballistically through the chamber having limited contact with ozone or $\mathrm{OH}$, and chemical reaction is less competitive with photolysis / photobleaching reactions of the aerosol. RTDs describe the probability of a fluid element's age inside the reactor; one can think of those as the probability distribution function (PDF) of a fluid element in the reactor (Fogler, 2006; Levenspiel, 1999). Tools are available to diagnose or predict flow behavior. These tools fall in two categories: tracer tests (diagnostics) and computational fluid dynamics (CFD) simulations (predictions).

We present a technique to assess the degree of plug flow in an OFR that can be in principle extended to any vessel. The rigor of the technique is tested by varying use of internals and flow rate and observing the resulting RTD curves in the Washington University PAM (WU-PAM) reactor. We begin by introducing an experimental method for obtaining the reactor RTD, which can be applied to any other OFR, via inert tracer injections. From raw data, we explain how to obtain PDFs. We chose to run CFD on the simplest design (a base case configuration) of the WU-PAM reactor to gain hydrody- 
namics information. Finally, we compare results from tracer tests and CFD for the base case. We compare this approach to that of previous studies by Lambe et al. (2011a), Huang et al. (2017), and Simonen et al. (2017), which to the best of our knowledge are the only other studies to date that report experimentally derived RTDs in OFRs. We do not provide predictive configurations for the PAM reactor because there are many avenues different groups can take depending on their focus, and this study is central to the current design.

\section{Methods}

The WU-PAM reactor is an iridite-treated aluminum cylinder, $18 \mathrm{in}$. in length and $8 \mathrm{in}$. in inner diameter, giving it a total volume of $13 \mathrm{~L}$. It has two 12 in. mercury lamps with peak wavelengths at 185 and $254 \mathrm{~nm}$ (BHK, Inc. Analamp model no. 82-9304-03) housed in Teflon sheaths, directly opposite each other, along the axial direction. Annular flow of $\mathrm{N}_{2}$ (Airgas) through the sheaths prevents direct contact with the lamps and purges any outgas products when the lamps are turned on. The mercury lamps are left in place with their housing to mimic simple OFR internals; they have not been turned on during this study. Details of their mode of operations for oxidant formation can be found elsewhere ( $\mathrm{Li}$ et al., 2015; Peng et al., 2015, 2016). OFRs like the WU-PAM have removable internals, face plates, and peripheral inlets and outlets that allow a wide variety of configurations. For example, Ortega et al. removed the inlet plate of their PAM reactor during a deployment in the Fire Lab at Missoula Experiment (FLAME-3) while keeping the inlet baffle to reduce particle loss, and in doing so observed a reduction in jetting of centerline flow (Ortega et al., 2013). In a different study, Lambe et al. (2011a) ran experiments keeping the inlet plate on the PAM coupled with a sparger (a cap with large holes in the side in fixed onto the inlet, so that the flow does not jet into the chamber), because laboratory experiments required a closed system (Lambe et al., 2011a).

In this work, we chose four configurations: I (one inlet, one outlet, two lamp housings as internals), II (one inlet, one outlet, two lamp housings with sparger and baffles as internals), III (multiple inlets, multiple outlets, two lamp housings as internals), and IV (multiple inlets, one outlet, two lamp housings with sparger and baffles as internals). Configuration I at $78 \mathrm{~s}$ spacetime was subject to a CFD simulation as a simple scenario where the simulation could capture hydrodynamics accurately.

\subsection{Tracer studies}

The laboratory setup to determine RTDs experimentally is shown in Fig. 1. $\mathrm{N}_{2}$ (Airgas) was the carrier fluid and $\mathrm{SO}_{2}$ (3 ppm; Air Liquide) was the inert tracer. Both flow rates were controlled by mass flow controllers (MFCs; Pneucleus Technologies, LLC). All experiments began by allowing $1 \mathrm{~h}$ to achieve a steady state of the carrier gas' flow profile inside the reactor, after which $\mathrm{SO}_{2}$ was introduced in a single step-up manner. A tracer flow rate of $100 \mathrm{~cm}^{3} \mathrm{~min}^{-1}$ allowed good detection in the measurement and minimized perturbation of the flow field. Analogously, the flow of the carrier fluid was stepped down to maintain the desired constant total volumetric flow rate. $\mathrm{SO}_{2}$ mixing ratios were determined by the Thermo Scientific model $43 i$-TLE Enhanced Trace Level $\mathrm{SO}_{2}$ Analyzer via pulsed fluorescence, and the instrument was set to an averaging time of $10 \mathrm{~s}$. This setting was the highest frequency over which the instrument could average the signal. Obtaining high-frequency data simplifies data analysis by avoiding the need for interpolation techniques, as discussed in Sect. S1.

We expected that the tracer would experience an associated spacetime and RTD in places other than the reactor, between the exit of the flow controller and the $\mathrm{SO}_{2}$ detection chamber in the gas analyzer. We therefore ran two experiments for every WU-PAM reactor configuration. The first incorporated both the reactor and the inlet and outlet plumbing, and the second bypassed the reactor. From these two signals we could extract the actual reactor RTD as described in Sect. 3.2. Both experiments were operated by allowing the formation of fully developed flow before injecting the tracer stepwise, as mentioned previously. Appendix A describes in detail how we obtained a PDF and a cumulative distribution function (CDF) from raw data.

The WU-PAM reactor has peripheral inlets and outlets to optionally create a ring (annular) flow around the centerline. Ideally, a uniformly distributed flow around the centerline helps stabilize the flow, avoids recirculation, and reduces wall losses. To create ring flow, we formed a $3 / 8$ in. Teflon tube into a circle, and drilled six 1/16 in. diameter holes evenly spaced along the side of the tube facing in the direction of flow. A similar Teflon tube circle was created for the outflow. The ring flow setup required additional plumbing internals (Fig. 1b). Tracer tests were accomplished for configuration I at three different spacetimes (of 52, 78, and $152 \mathrm{~s}$ ), for three different configurations (I, II, and III) at $78 \mathrm{~s}$ spacetime, and an arbitrary special case for configuration IV at $411 \mathrm{~s}$ spacetime (configuration and spacetime not commonly used).

\subsection{Simulations}

While tracer studies are a powerful diagnostic tool and result, if done correctly, in accurate RTDs, they cannot capture the full hydrodynamics details, or the state of mixing in the reactor (i.e., the exchange of mass between the fluid elements). Both hydrodynamics and mixing can significantly influence the reactor performance (Fogler, 2006; Villermaux, 1986). For configuration I at $78 \mathrm{~s}$ spacetime, we ran a CFD simulation to visualize the hydrodynamics inside the WU-PAM. This comparative analysis seeks to provide validation prior 


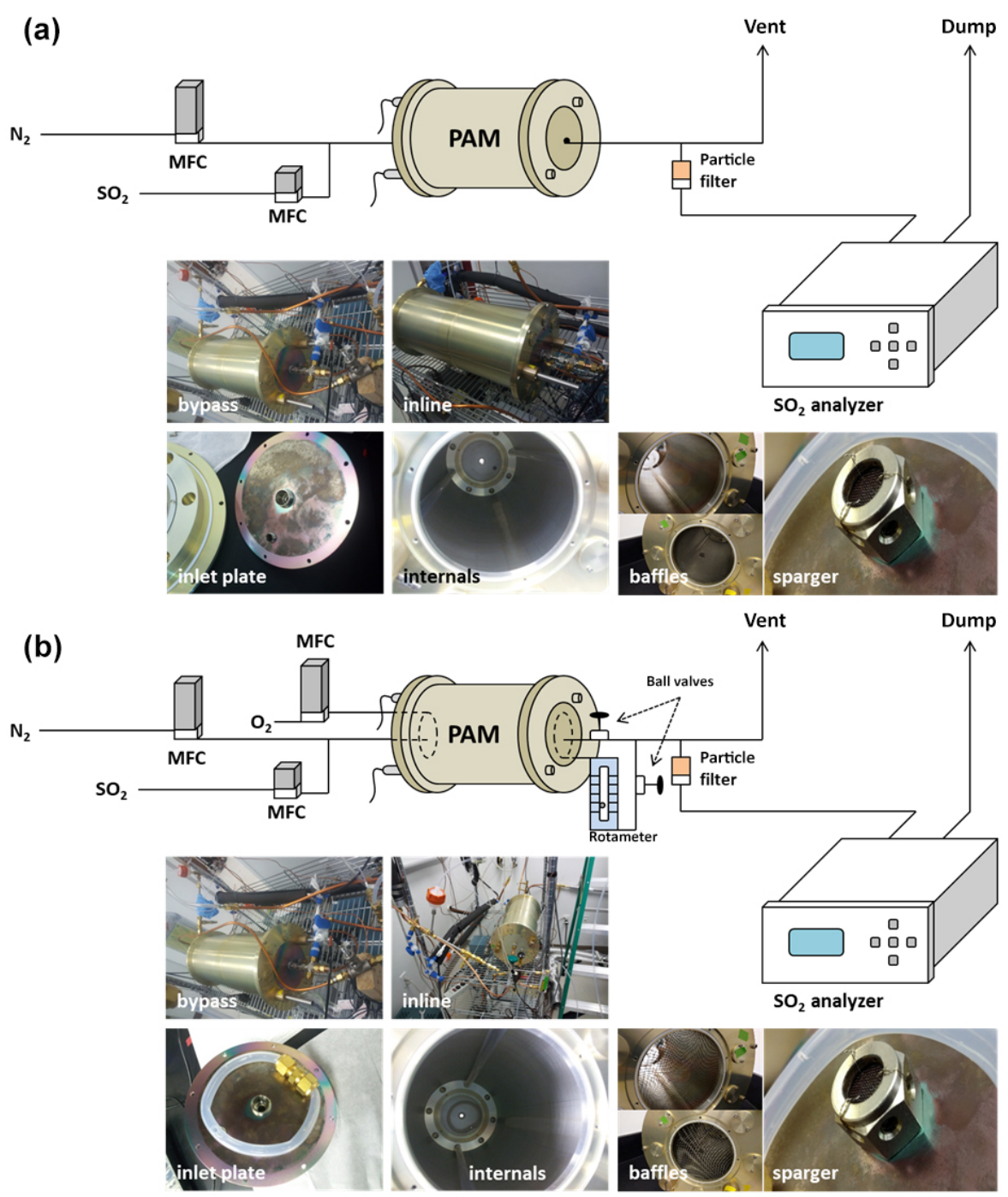

Figure 1. Experimental setup for tracer studies for (a) one inlet and one outlet and (b) peripheral inlets and outlets. The main difference is the presence of the ring sparger in (b).

to using the CFD platform as a predictive tool for mixing patterns in OFRs with more complex geometry or internals.

As a solver, we used OpenFOAM, an open-source CFD toolbox available at www.openfoam.com and www. openfoam.org. The reactor geometries were constructed on FreeCAD, an open-source computer aided design (CAD) software available at www.freecadweb.org, and Onshape, available at www.onshape.com, prior to being exported into OpenFOAM. To discretize the volume elements in the geometry, a mesh was created using the snappyHexMesh tool in OpenFOAM either directly or in the HELYX-OS graphical user interface (GUI). HELYX-OS is an open-source GUI produced by ENGYS (www.engys.com). By generating mainly hexahedral meshes, this tool can mesh objects of irregular shape. Then, additional layers of different geometry are added to the surface to improve the mesh quality. A figure and details of the mesh can be found in Fig. S1 and Table S1, respectively. The hydrodynamics were calculated using simpleFoam, a steady-state solver for single-phase incompressible laminar or turbulent flow. We used first-order schemes, and specified the boundary conditions in each simulation case. The outlets had zero gradient for velocity and fixed values for pressure, while the walls had fixed value for velocity and zero gradient for pressure. After the flow field is obtained, a tracer experiment is simulated by scalarTransportFoam for one of the simulations, which solves the transient convection-diffusion transport equation of a passive scalar (dimensionless tracer concentration in this case). The initial condition is zero concentration, and the boundary condition at the inlet is that the dimensionless tracer concentration is equal to 1 . After the simulation, the exit concentration is mixing-cup averaged to output a representative of a 

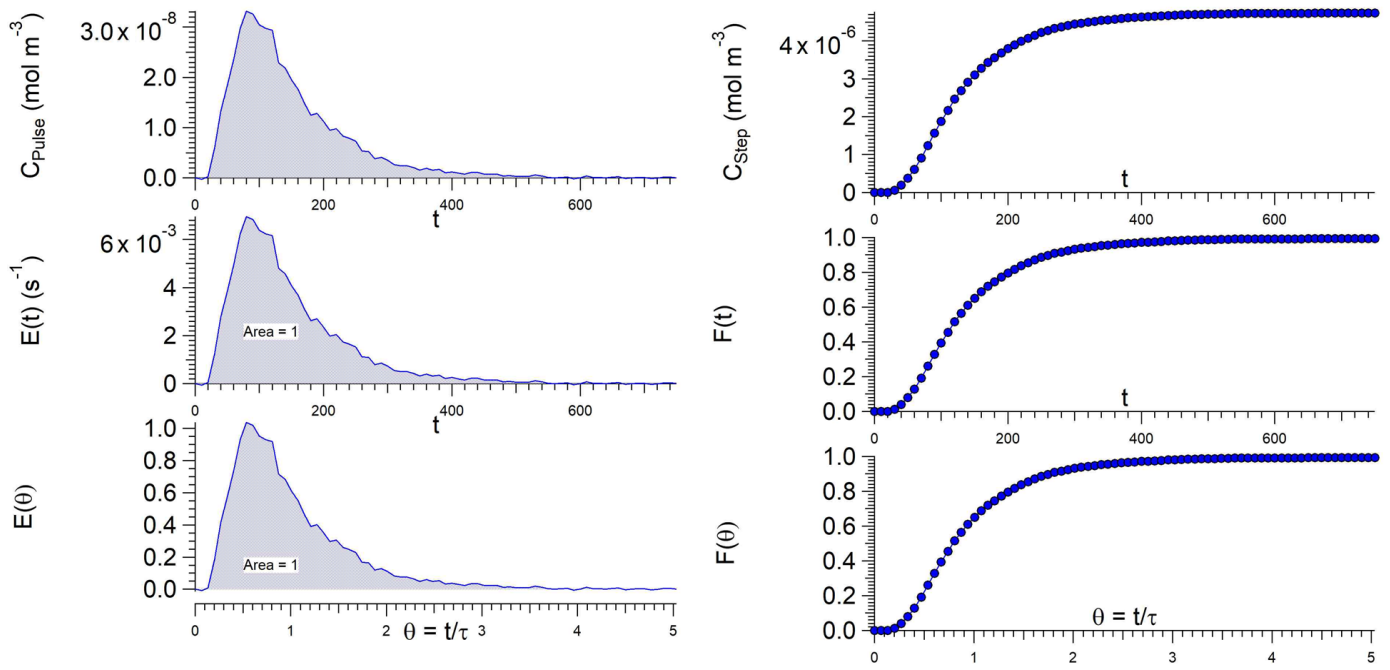

Figure 2. Tracer tests at $10 \mathrm{~L} \mathrm{~min}^{-1}$ (78 s spacetime) through the reactor for configuration I. This figure serves as an illustrative example for non-dimensionalizing tracer response curves.

cumulative RTD (explained in the next section). We added a modification to the existing solver to account for turbulent diffusivity, which had a non-negligible effect on mixing in the WU-PAM reactor, particularly at the entrance jet for high flow rates. We found that the turbulent diffusivity was on the same order of magnitude as the molecular diffusivity within the jet region near the inlet, suggesting turbulence in the jet was significant. It is worthwhile to note that the inlet sparger and baffles (i.e., internals present in configuration II and IV) left out of the simulation could significantly affect this outcome. However, resolving the simulation mesh size to account for these internals significantly extended the computational requirements, to the point that running these simulations was not possible on our computer system and would require a computing cluster to perform.

\section{Results}

\subsection{The RTD function, $E(t)$, and the cumulative RTD function, $F(t)$}

Tracer tests give us fast qualitative information about the reactor, but mathematical manipulation (e.g., normalizing the data and scaling the axes) of the data provides quantitative information and offers a basis for comparing reactor behaviors on a universal scale. The main mathematical descriptors of a fluid element residing in a chamber are its PDF and its CDF. For a chemical reactor, the PDF is more commonly referred to as the RTD function, $E(t)$, in the dimensional domain, or $E(\theta)$ in the dimensionless domain (referred to as E curves). Similarly, the CDF is called the cumulative RTD function, $F(t)$, in the dimensional domain, or $F(\theta)$ in the dimensionless domain (referred to as F curves; Danckwerts, 1953; MacMullin and Weber Jr., 1935). The relations between E curves and $\mathrm{F}$ curves are derived for the reader in this Appendix A, but are well established and available on the internet and in classical textbooks (Fogler, 2006; Levenspiel, 1999, 2002).

Figure 2 gives an example of how mathematical processing of the data looks. The shape of the curve does not change, but the axes do. Section S1 explains how we obtained a pulse response equivalent of concentration data from stepwise addition of the tracer.

In the WU-PAM, advective flow should be the main form of transport (we do not consider convective effects due to thermal gradients from lamp activity in this work). Modeling real reactors can be challenging, but approximations are possible using ideal reactor concepts (Levenspiel, 2002). The two most common examples of ideal reactors are the plug flow reactor (PFR), where the flow is perfectly plugged or piston-like, and the continuously stirred tank reactor (CSTR), where the flow is perfectly mixed. Mathematically, their E curves are represented by Eqs. (1)-(4):

$E_{\mathrm{PFR}}(t)=\delta(t-\bar{t})$,

$E_{\mathrm{PFR}}(\theta)=\delta(\theta-1)$,

$E_{\operatorname{CSTR}}(t)=\frac{1}{\bar{t}} e^{-\frac{t}{\bar{t}}}$

$E_{\mathrm{CSTR}}(\theta)=e^{-\theta}$.

Examples of how RTDs look like based on compartmental modeling using both ideal reactors are available in chemical engineering textbooks (Fogler, 2006; Levenspiel, 1999) and, although not discussed here, a variety of phenomenological models can be applied to describe or compare OFRs. It is then open to interpretation whether the combination of ideal reactors chosen for an E curve (e.g., a PFR and CSTR in series, or two CSTRs in parallel) describes the hydrodynamics of the reactor as well. The RTD of an OFR should 
be obtained experimentally, if possible, before deciding what model to use to describe it. Development of a phenomenological model to describe the WU-PAM RTD is beyond the scope of this study, the aim of which is to develop a robust methodology to assess degree of plug flow in any OFR; however, this is an avenue that should be pursued in the future. Given our current setup at Washington University, the true reactor RTD is impossible to measure accurately by a single tracer injection. The tubing length, pressure drop inside the filter holder upstream of the $\mathrm{SO}_{2}$ detector, and location of the $\mathrm{SO}_{2}$ detector have not been minimized; thus we expect that collectively they could perturb our measurements significantly. We choose not to simply subtract the theoretical space time of the tubing, because non-ideal tracer injection or detection are most likely not represented by a Dirac function of a perfect impulse (or derived from a perfect stepwise injection, represented by the Heaviside function). Therefore we need to deconvolute the RTD signal due to the reactor from the signal due to additional plumbing.

\subsection{Tank-in-series model for indirect deconvolution}

In the author's textbook (Levenspiel, 1999), Levenspiel describes the convolution integral, which has been adapted to solve previous problems of decoupling RTD signals (Hamed, 2012; Han, 2007; Mills and Duduković, 1988; Simonen et al., 2017; Sun, 2010). This integral focuses on packets of the tracer that enter $t^{\prime}$ seconds before $t$, which is $\left(t-t^{\prime}\right)$, and stay $t^{\prime}$ seconds in the reactor:

$C_{\text {out }}(t)=\int_{0}^{t} C_{\text {in }}\left(t^{\prime}\right) \cdot E\left(t-t^{\prime}\right) \mathrm{d} t^{\prime}$,

or

$C_{\text {out }}(t)=C_{\text {in }} * E$,

where $E$ is the true $\mathrm{E}$ curve of the reactor, and $C_{\text {in }}$ and $C_{\text {out }}$ are the time-dependent concentration profiles of the measured tracer at the injection port and outlet port, respectively. This equation is based on assumptions of mass conservation (i.e., no wall loss inside the reactor) and memory loss (i.e., the fluid elements in fast-moving fluid in a region are not bound to behave as fast-moving in another region). We separate two regions in our setup, and identify three E curves. These correspond to curves for the reactor, the plumbing (including filters, instrument plumbing, and the instrument detector chamber), and the two together. Respectively, we denote them as $E_{0}(t), E_{1}(t)$, and $E_{2}(t)$. We are able to accurately measure $E_{2}(t)$ and $E_{1}(t)$, but not $E_{0}(t)$. Thus, Eq. (6) now takes the form

$$
E_{2}(t)=E_{0}(t) * E_{1}(t),
$$

and we need to solve for $E_{0}(t)$. Details of the deconvolution approach can be found in Appendix B; however, direct application of this technique failed to get the solution to converge.
It is a robust protocol to accurately determine a numerical RTD, and should be applied whenever a stable solution is available.

What we propose is an indirect application, i.e., to guess $E_{0}(t)$ so that the convolution integral yields a curve that matches that of $E_{2}(t)$. This requires a formidable number of guesses and iterations and could be a lengthy process if done numerically. One workaround is to assume a form of $E_{0}(t)$, ideally with one variable parameter, which can be tuned to give the $E_{2}(t)$ that best matches the experimental $E_{2}(t)$ curve. The CSTR and PFR forms should not be considered since they are ideal extremes of reactor behavior. We chose to apply the tank-in-series (TIS) model (MacMullin and Weber Jr., 1935), also referred to as the N-CSTR model, to the convolution integral since it is a one-parameter model that, although not specific to flowtube, tubular, laminar, or plug-flow reactors, gives an idea of where the reactor lies on the spectrum of mixed flow vs. plugged flow based on the value of a parameter, $N . N$ refers to the fictitious number of equivalent CSTRs that, in series, describe the $\mathrm{E}$ curve for the reactor. This function is

$$
\begin{aligned}
& E(t)=\frac{t^{N-1}}{(N-1) !\left(\frac{\bar{t}}{N}\right)^{N}} e^{-\left(\frac{N}{\bar{t}}\right) t}, \\
& E(\theta)=\frac{N(N \theta)^{N-1}}{(N-1) !} e^{-N \theta} .
\end{aligned}
$$

For a value of $N=1$, the E curve becomes that of a perfect CSTR; for a value of $N=$ infinity, it becomes that of a perfect PFR, as shown in Fig. S2. Using this model, the convolution integral takes the form

$$
E_{2}^{*}(t)=\int_{0}^{t} E_{1}\left(t-t^{\prime}\right) \cdot \frac{t^{\prime N-1}}{(N-1) !\left(\frac{\bar{t}}{N}\right)^{N}} e^{-\left(\frac{N}{\bar{t}}\right) t^{\prime}} \mathrm{d} t^{\prime},
$$

where $E_{1}\left(t-t^{\prime}\right)$ is an array of accurate experimental data already obtained, and $E_{2}^{*}(t)$ is the output guess. $E_{2}^{*}(t)$ is then matched to $E_{2}(t)$ by varying $N$ in an iterative fashion. Using this form, the algorithm in Appendix B is still valid. We used MATLAB to solve this for all cases. The results are displayed in Fig. 3.

\section{Discussion}

The small aspect ratio of the WU-PAM limits wall interactions, preventing laminar flow development due to absence of a boundary layer. This suggests the flow field would then depend on inlet/outlet geometries or volumetric flow rate. However, for a fixed spacetime of $78 \mathrm{~s}$, we observed that different configurations had no significant effect on the RTD (Fig. 3b, d, e). Further, for configuration I, different spacetimes also had no significant effect. The only case with a marked change in the signal was for configuration IV at $411 \mathrm{~s}$ 
spacetime (Fig. 3f). We attribute this difference to the low volumetric flow rate, implying that advective transport begins to be less dominant than turbulent or molecular diffusivity as mode of transport. Such a low spacetime, while increasing the degree of plug flow, would result in a potentially significant loss of semivolatile or low-volatility gases. Additionally, other modes of transport such as convective effects (vertical mixing for non-isothermal conditions) could become more apparent, as revealed by Huang et al. (2017) for the Caltech photooxidation flow tube (CPOT) reactor. As mentioned earlier, a detailed phenomenological modeling study of RTDs in the WU-PAM is beyond the scope of this study; however, at more conventional spacetimes, it would be helpful to visualize hydrodynamics to assess what contacting patterns and state of mixing the reactor exhibits. We thus chose a simple scenario as a base case for simulation: configuration I at $78 \mathrm{~s}$ spacetime.

CFD reveals that the hydrodynamics inside the PAM are far from that of a well-mixed reactor (Fig. 4). This is insightful because the $\mathrm{F}$ curve of the simulation matches reasonably well with that of the experiment (Fig. 5) and alone would imply CSTR-like mixing. This is the caveat associated with interpreting RTDs, and further supports investigation in phenomenological modeling. Snapshots of the simulation displayed in Fig. 4a-c show there is jetting (short-circuiting), recirculation, and dead zones. Jetting leads to fluid elements that have a very short residence time and cause high values of $E(t)$ at $t>0 \mathrm{~s}$. Recirculation leads to fluid elements spending more time in the reactor, yielding middle values of $E(t)$ as elements exit at $t \sim \bar{t}$. Stagnation (dead zones) at the inlet of the reactor cause fluid elements to remain entrained in the reactor for a long time before exiting the reactor at $\sim 2$ $3 \times \bar{t}$ at low values of $E(t)$, leading to a long tail in the $\mathrm{E}$ curve. These three effects together lead to an E curve that looks similar to that of a CSTR, but mixing in CSTRs is dominated by recirculation, meaning that the local concentration of tracer at the exit is identical to all other locations in the reactor (Zwietering, 1959). Therefore, while tracer tests give a general idea about contacting patterns, CFD visualizes the hydrodynamics, and help model the reactor. Plotting the WU-PAM OFR's E curves for this scenario on a semi-log plot does not yield different gradients, which would otherwise indicate different volumes for the compartmental modeling of the jetting, recirculation, and dead volumes (Levenspiel, 2002). The limitation to that statement is that the E curves in this work have been obtained by fitting a oneparameter model, the consequences of which should be the focus of future work in conjunction with phenomenological modeling. Furthermore, our simulations are limited to isothermal conditions, and therefore cannot predict buoyancy effects that could explain spread in the RTD at low flow rates (or low Reynolds numbers; Fig. 3f), as observed by Huang et al. (2017).

Lambe et al. (2011a) modeled the Pennsylvania State University PAM (PSU-PAM) reactor using a compartmen-

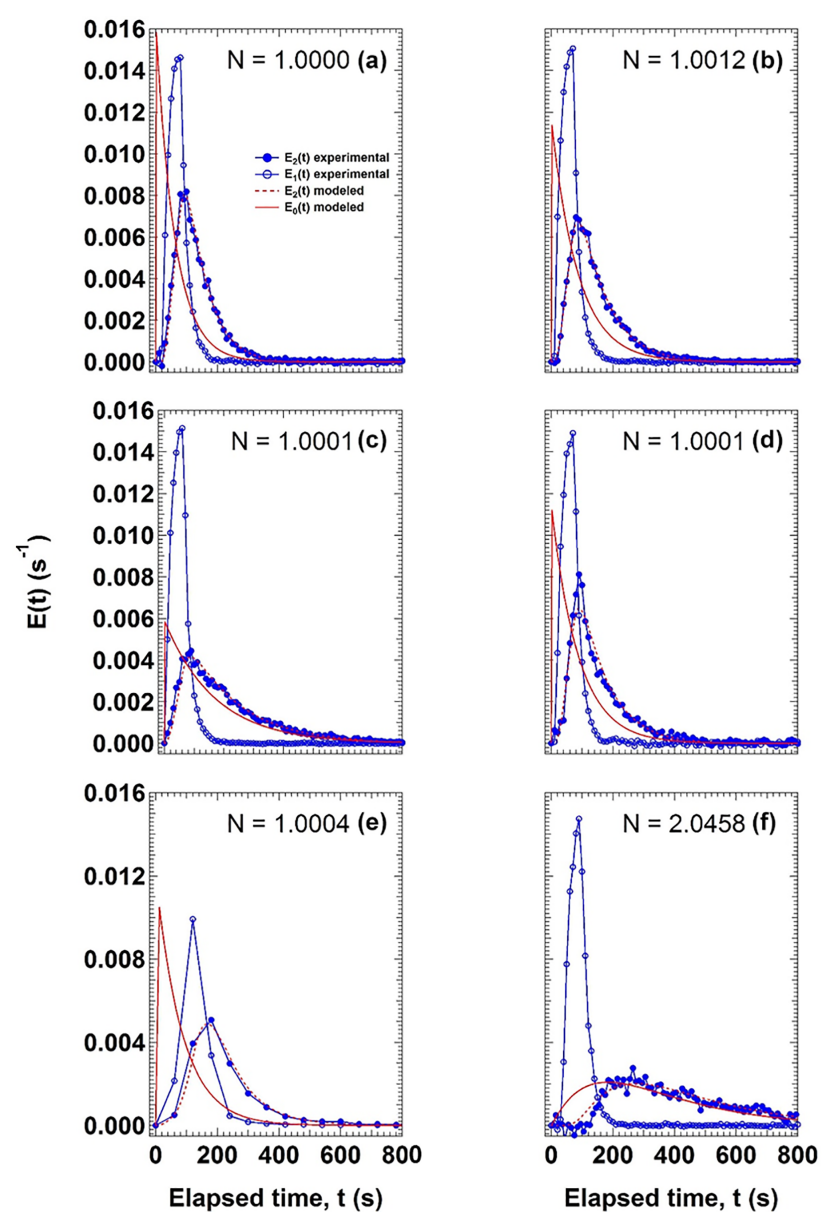

Figure 3. E curves for the WU-PAM configuration I at (a) $52 \mathrm{~s}$, (b) $78 \mathrm{~s}$, and (c) $156 \mathrm{~s}$ spacetimes, at $78 \mathrm{~s}$ spacetimes for (d) configuration II, (e) configuration III, and (f) for configuration IV at $411 \mathrm{~s}$ spacetime. Details on the configurations are in the Methods section. Lower-frequency data for panel (e) were due to instrument repair, and temporarily set on longer averages.

tal model consisting of two parallel tubular reactors that exhibit Taylor dispersion (Taylor, 1953), suggesting that their reactor (whose geometry is identical to that of the WU-PAM OFR) has two main volumes: an active reactor volume and another volume with entrainment. The model output matches their experimental data reasonably well, but they did not decouple the reactor's E curve from that of the setup, implying the match may include phenomena occurring in other pipes of the setup. Lambe et al. describe RTDs for the two volumes using the axial dispersion model (ADM; Taylor, $1953,1954 a, b)$, which is based on modeling plug or laminar flow with axial dispersion of material. Generally, as also stated by Huang et al. (2017), the ADM is valid for regions where the radial Péclet number $\left(P e_{\mathrm{r}}\right)$ is less than $\sim 4$ times the aspect ratio (length of reactor divided by its cross sectional area), or if $P e_{\mathrm{r}}$ is greater than $\sqrt{ } 48$ (Aris, 1956; Taylor, 1954b). Both the PSU-PAM OFR and the WU-PAM OFR 


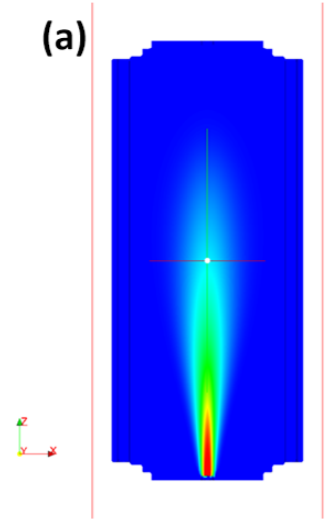

(b)

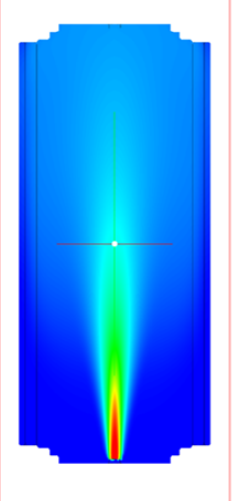

(c)

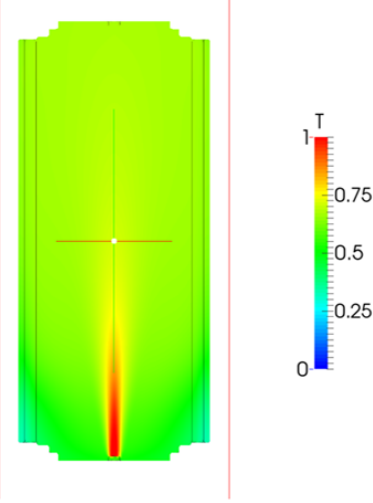

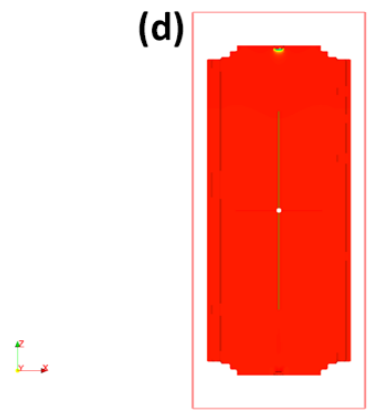
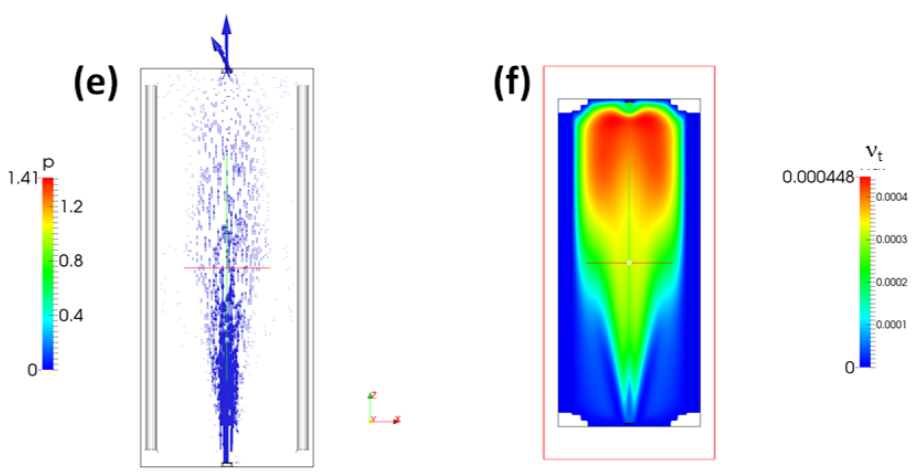

Figure 4. CFD output for configuration I at $78 \mathrm{~s}$ spacetime: snapshots at (a) $1 \mathrm{~s}$, (b) $10 \mathrm{~s}$, and (c) $100 \mathrm{~s}$ of runtime, and (d) pressure field, (e) velocity (vector) field, and (f) turbulent diffusivity field. Color scales are dimensionless scalar concentration for the tracer (a-c), bar for the pressure field (d), and cSt for the kinematic viscosity (f).

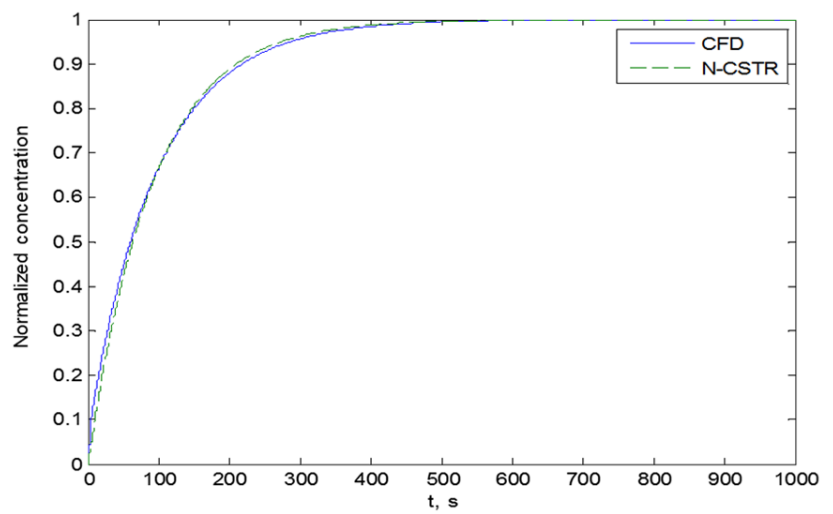

Figure 5. Comparison of F curve output between simulation (CFD) and tracer test (N-CSTR) for configuration I at $78 \mathrm{~s}$ spacetime. NCSTR is an acronym (describing "N" CSTRs in series) equivalent to TIS: both refer to the tank-in-series model (see Sect. 3.2).

meet these requirements under typical flow rates (see Supplement, Sect. S4). If the reactor could be described by the ADM, CFD would show that the entrance and exit effects would be separate from the main flow in the tube - which is not the case for the simplified geometry of configuration
I. We do not know how well they apply to the other configurations. At no point inside the reactor does pipe flow fully develop, so the high aspect ratio concept (Kang et al., 2007) does not allow a velocity profile to become established with the current end caps used. Thus, although $P e_{\mathrm{r}}$ appears acceptable, the inlet and outlet regions should be re-engineered to allow formation of fully developed pipe flow in the main cylinder for the ADM to be valid. While the E curve for configuration II is similar to that of configuration I at $78 \mathrm{~s}$ spacetime, it would be helpful to run CFD on that configuration at different spacetimes to observe if, and if so at what spacetime, the sparger and baffles efficiently suppress jetting. Unfortunately, our CFD mesh could not be refined enough to capture the geometry of those without sacrificing valuable computational time.

Instead, we chose to apply the use of an inlet cone $\left(45^{\circ}\right.$ angle, 4.94 in. length) and outlet peripherals to simulate a more attenuated inlet and exit from sudden aperture. The results are displayed in Fig. 6. While the size of the jet appears to be broader compared to simulations in Fig. 5 (unaltered PAM geometry), it is nonetheless present. Furthermore, recirculation in the form of backmixing is evident towards the front, and stagnation close to the walls and corners persists. From the velocity field (Fig. 6b), a smaller cone angle that follows 


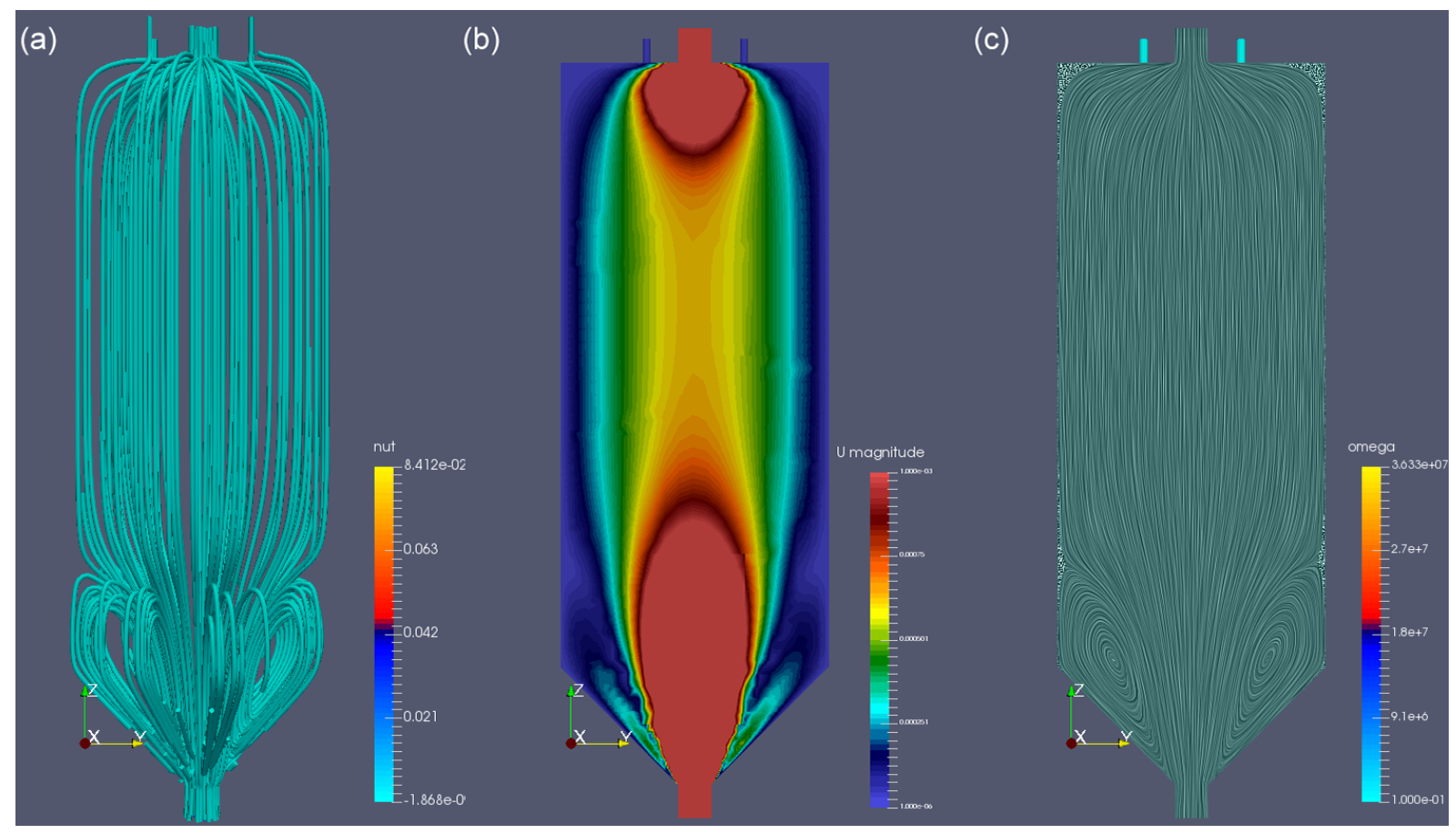

Figure 6. CFD analysis on the effect of inlet cone and peripheral outlets on fluid flow. All figures represent a visualization of the flow field, with color scales representing (from left to right): kinematic viscosity, velocity, and $\omega$. The 3-D representation in panel (a) highlights the uniformity of the recirculation region.

the contour of the light blue velocity field could prevent backmixing.

\section{Potential implications}

Initial PAM modeling work assumed plug flow behavior in OFRs (Li et al., 2015). Li et al. stated that correcting for the non-ideal $\mathrm{E}$ curve in their OFR would account for $\sim 10 \%$ error in their oxidant exposure results, which is less than the overall model uncertainty. However, recent work incorporates the effect of non-ideal RTDs on model outputs (Palm et al., 2017, 2018, Peng et al., 2015, 2016, 2017; Peng and Jimenez, 2017). Peng et al. (2015) show that for three OFR operational modes (that is, modes of different oxidant formation mechanisms denoted by OFR185, OFR254-70, and OFR254-7), a comparison between model output for ideal plug flow vs. non-ideal RTDs (using the RTD experimentally obtained by Lambe et al., 2011a) for $\mathrm{OH}$ exposure $\left(\mathrm{OH}_{\exp }\right)$ generally agree within a factor of 2 for low $\mathrm{OH}_{\text {exp }}$; the model disagreement is exacerbated at high $\mathrm{OH}_{\exp }$ beyond a factor of $\sim 4$. Peng and Jimenez (2017) then extend OFR operational modes to include $\mathrm{N}$-containing chemistry (in modes referred to therein as OFR185-iNO, OFR185-7-iNO, and OFR18570-iNO) where at moderate-to-high $\mathrm{OH}_{\text {exp }}$, the deviations are exacerbated significantly, although the authors argue those conditions represent unrealistic chemical pathways. It is worthwhile noting that the chemistry modeled by Peng and Jimenez may find a workaround by utilizing $\mathrm{N}_{2} \mathrm{O}$ as $\mathrm{NO}$ precursor (Lambe et al., 2017) rather than NO itself, potentially minimizing RTD-related errors. Palm et al. (2018) report data from OFR field deployment where the same comparison (ideal plug flow vs. the RTD experimentally obtained by Lambe et al., 2011a) suggests RTD-related errors overpredict (for $\mathrm{CO}$ ) or underpredict (for toluene and monoterpenes) photochemical age (that is, the ratio of $\mathrm{OH}$ exposure to tropospheric average $\mathrm{OH}$ number concentrations) in the reactor, generally within a factor of 3 of model error. Considering this work employs the compartmental model RTD described by Lambe et al. (2011a), which for reasons mentioned in the previous section may not be the true PAM RTD, and given that non-ideality in RTDs affects certain OFRs more than others, implementing the method presented here to obtain a more representative reactor RTD can either help constrain error uncertainty in the models, or possibly extend the $\mathrm{OH}_{\text {exp }}$ range in which OFRs can be operated, a reportedly nontrivial task (Palm et al., 2018). Considering our results indicate that OFRs like the WU-PAM exhibit an RTD closely matching that of an ideal CSTR, which is more well mixed than the Lambe et al. RTD, the sensitivity analysis conducted so far could represent a lower bound for error analysis because the Lambe et al. (2011a) RTD is closer to a PFR-like RTD than a CSTR-like RTD.

For compounds with low lifetimes to $\mathrm{OH}$, contacting could influence the model results to a greater extent (e.g., field de- 
ployment monoterpene decay reported by Palm et al., 2018). By taking a ratio of characteristic reaction time to the characteristic transport time, one can define the Damköhler number $\left(D a_{n}\right)$. Considering spacetimes of $52-411 \mathrm{~s}$ (as per this study), the value of $D a_{n}$ can be between 0.52 and 4.11 for a compound with lifetimes of $\sim 100 \mathrm{~s}$. Since reaction timescales are on the order of transport timescales, contact patterns may play an important role, as seen in Palm et al. (2018). This could also be the case for heterogenous reactions, diffusion-limited reactions, or semivolatile compound (SVOC) oxidation that exhibit slow gas-particle partitioning. Furthermore, combining a phenomenological model to an associated RTD can impact kinetics (and yields) further. The RTD generated by Lambe et al. (2011a) employed in Li et al. (2015) may lead to greater than $10 \%$ error if the two PFRs in parallel model suggested by Lambe et al. (2011a) are not applicable. In these scenarios, ensuring a high degree of plug flow can not only maximize exposure, but minimize the distribution of aged compounds (e.g., first- or secondgeneration compounds) that are due to different exit ages because of recirculation or stagnation. However, this configuration may not suit a field deployment where trace compounds have short lifetimes to $\mathrm{OH}$ and can be easily lost to reactor walls, in which case ensuring a high degree of mixing would be beneficial.

We do recognize that OFR (or any environmental chemical reactor) users may have a preference to rapidly obtain an RTD profile perhaps using an improvised setup with very short sample lines and a fast time-response gas analyzer. However, the accuracy to which the profile is obtained should be carefully examined. If the reactor is considerably large, or if it is an OFR to be deployed for low levels of exposure, then the influence of plumbing is minimal. If the reactor of choice is small, the oxidant exposure is high, or the reactor has more than one inlet/outlet or other peripheral components, it would be recommended to use the method described here to obtain the most representative RTD, since all sources of bias are removed.

\section{Conclusion}

The WU-PAM reactor's hydrodynamics are complex, and even though the E curve looks simple, applying a compartmental model (phenomenological modeling) to obtain an analytical E curve (rather than the empirically based TIS E curve) can be challenging. Having too sudden an aperture at the entrance zone leads to dead volumes at the inlet corners. We cannot confirm if the sparger design helps reduce dead volume, but tracer tests suggest it does not appear to affect the degree of plug flow under standard operating spacetimes (52-156 s). The reactor is not described by back mixing, plug flow, or by the ADM in any configuration. However, for configuration IV at $411 \mathrm{~s}$ spacetime, a noticeable shift towards plug flow behavior is observed, perhaps due to a combined effect of internals and low inlet velocity. We note that the $\mathrm{E}$ curves we obtain are not as accurate as an E curve numerically obtained by direct deconvolution, since we are forcing a closed form solution on our data. We further note the need for phenomenological modeling.

Tapered ends on the inlet and the outlet would help to develop a steady flow profile at the inlet and avoid recirculation at the outlet, however the cone angle should be predetermined by CFD if possible. By improving simulations to include temperature gradients induced when the internal lamps are on, and refining the mesh to capture internals, the ADM should be revisited as a model to describe the PAM reactor. If the ADM satisfactorily describes the PAM reactor's RTD, kinetics should be easier to obtain, and even diffusivity values using the Aris-Taylor relationship (Aris, 1956) can be obtained. This could help assess whether processes are reaction limited or diffusion limited, supporting reactor validity in experimental setups. At that point, the reactors would be regulated by only one parameter, their flow rate. This parameter would be adjusted to achieve desired spacetimes depending on $\mathrm{OHR}_{\text {ext }}$. Finally, to obtain accurate experimental RTDs, achieving a functional direct deconvolution code should be a focus of future development. The implementation of this technique can be extended to drift tubes in mass spectrometers, as those are essentially flow tube reactors where ionization efficiency can be strongly influenced by mixing.

Data availability. Data from this work can be made available upon request through the contact author. 


\section{Appendix A: The use of $E$ and $F$ curves}

To determine RTDs, we injected tracer in a steady stream rather than a single pulse. This prolonged and constant injection, which we call a step input, gave us $F(t)$, from which we can derive $E(t)$ as follows:

$$
\begin{aligned}
& F(t)=\frac{v}{m} C_{\text {step }}, \\
& E(t)=\frac{\mathrm{d} F(t)}{\mathrm{d} t},
\end{aligned}
$$

where $v$ is the volumetric flow rate in $\mathrm{m}^{3} \mathrm{~s}^{-1}, m$ is the molar flow rate of the tracer in $\mathrm{mol} \mathrm{s}^{-1}$, and $C_{\text {step }}$ is the concentration of the tracer for a step input in $\mathrm{mol} \mathrm{m}^{-3}$. Therefore, $F(t)$ is dimensionless, and $E(t)$ in this example has units of $\mathrm{s}^{-1}$. The area under the E curve is unity, representing the PDF of the system:

$$
\int_{0}^{\infty} E(t) \mathrm{d} t=1 .
$$

Similarly, for the dimensionless domain

$$
\int_{0}^{\infty} E(\theta) \mathrm{d} \theta=1,
$$

and if we take $\bar{t}$ to be the mean residence time of the reactor, then

$$
\theta=\frac{t}{\bar{t}} .
$$

The additional utility of the dimensionless domain is that for reactors of different sizes, built to behave the same, the RTD is numerically identical. For example, if PAM OFRs are operated in different ways (e.g., they operate at different flow rates) or are built in different sizes but display the same E curve in the dimensionless domain, then their performance will be identical, and their mean residence time will always occur at $\theta=1$. This identity would apply for the $\mathrm{F}$ curve as well in both domains, where from Eq. (A2) we can see that

$$
\begin{aligned}
& F(t)=\int_{0}^{t} E(t) \mathrm{d} t, \\
& F(\theta)=\int_{0}^{t} E(\theta) \mathrm{d} \theta .
\end{aligned}
$$

The mathematical properties of interest for PDFs are their moments: these have quantitative meanings in $\mathrm{E}$ curve analysis. A general equation for the moments of a function $f(x)$ is

$$
\mu_{n}=\int_{-\infty}^{\infty} x^{n} \cdot f(x) \mathrm{d} x
$$

where $\mu_{n}$ is the $n$th moment of the distribution. If we consider a raw $C(t)$ dataset from our tracer, we can derive the moments:

$$
\begin{aligned}
& \frac{\int_{0}^{\infty} C(t) \mathrm{d} t}{\int_{0}^{\infty} C(t) \mathrm{d} t}=\int_{0}^{\infty} E(t) \mathrm{d} t=1=\mu_{0}, \\
& \frac{\int_{0}^{\infty} t \cdot C(t) \mathrm{d} t}{\int_{0}^{\infty} C(t) \mathrm{d} t}=\int_{0}^{\infty} t \cdot E(t) \mathrm{d} t=\bar{t}=\mu_{1} .
\end{aligned}
$$

Here, we are interested in the first moment, which represents the mean residence time. For higher moments, we use the central moments of the distribution since we are interested in quantities like variance, skewness, and kurtosis around the mean (and not around zero). This alters Eq. (A8) as follows:

$\mu_{n}=\int_{-\infty}^{\infty}(x-a)^{n} \cdot f(x) \mathrm{d} x ; n \geq 2$,

where $a$ is a constant, and is generally the mean of the distribution ( $\bar{t}$ in this case). Thus, the second (central) moment of the $\mathrm{E}$ curve becomes

$$
\frac{\int_{0}^{\infty}(t-\bar{t})^{2} \cdot C(t) \mathrm{d} t}{\int_{0}^{\infty} C(t) \mathrm{d} t}=\int_{0}^{\infty}(t-\bar{t})^{2} \cdot E(t) \mathrm{d} t=\sigma^{2}=\mu_{2},
$$

where $\sigma^{2}$ has a clear physical meaning, and is the variance around the mean. Higher moments (skewness and kurtosis) can be of use, and require additional math, but are not addressed in this work.

\section{Appendix B: Algorithm for direct deconvolution}

Here, we perform an inverse operation to Eq. (7) (Sun, 2010) and work towards an output curve:

$E_{2}(t)=\int_{0}^{t} E_{1}\left(t-t^{\prime}\right) E_{0}\left(t^{\prime}\right) \mathrm{d} t^{\prime}$,

where $E_{0}$ is the RTD of interest, $E_{1}$ is the RTD of another component in series with $E_{0}$, and $E_{2}$ is the convoluted RTD. The deconvolution task is to solve for $E_{0}$ with measured $E_{1}$ and $E_{2}$. Due to the unknown function forms of $E_{1}$ and $E_{2}$, the integral is most easily resolved numerically. Thus, the time is discretized into $t_{i-1} \leq t \leq t_{i}$, where $t_{i}=i \Delta t, i=0 \ldots \infty$. The time interval $\Delta t$ is determined by 
the data acquisition frequency for $E_{1}$ and $E_{2}$, and is small enough to resolve the RTDs in fine detail. An even smaller $\Delta t$ is also feasible by interpolating the data at the finer temporal resolution. Equation (B1) is now rewritten as follows:

$$
\begin{aligned}
E_{2}\left(t_{i}\right) & =\int_{0}^{t_{i}} E_{1}\left(t_{i}-t^{\prime}\right) E_{0}\left(t^{\prime}\right) \mathrm{d} t^{\prime} \\
& =\sum_{j=1}^{i} \int_{t_{j-1}}^{t_{j}} E_{1}\left(t_{i}-t^{\prime}\right) E_{0}\left(t^{\prime}\right) \mathrm{d} t^{\prime} .
\end{aligned}
$$

Within the small interval between $t_{j-1}$ and $t_{j}$, we can assume $E_{1}$ and $E_{0}$ to be either constant (zeroth order) or linear with time (first order). Obviously the first-order approximation is more accurate than the zeroth order with a little more complexity in the integration. Both methods have been tested and proven to result in similar deconvoluted RTD, indicating that zeroth order is good enough with sufficiently small $\Delta t$. Thus the following derivation takes the zeroth-order simplification; i.e., for $t_{j-1} \leq t^{\prime} \leq t_{j}$ :

$$
\begin{aligned}
E_{1}\left(t_{i}-t^{\prime}\right) & =\frac{1}{2}\left(E_{1}\left(t_{i}-t_{j-1}\right)+E_{1}\left(t_{i}-t_{j}\right)\right) \\
& =\frac{1}{2}\left(E_{1}\left(t_{i-j+1}\right)+E_{1}\left(t_{i-j}\right)\right) \\
& =\frac{1}{2}\left(\left.E_{1}\right|_{i-j+1}+\left.E_{1}\right|_{i-j}\right)
\end{aligned}
$$

$$
\begin{aligned}
E_{0}\left(t^{\prime}\right) & =\frac{1}{2}\left(E_{0}\left(t_{j-1}\right)+E_{0}\left(t_{j}\right)\right) \\
& =\frac{1}{2}\left(\left.E_{0}\right|_{j-1}+\left.E_{0}\right|_{j}\right),
\end{aligned}
$$

which are Eqs. (B3) and (B4) with simplified notation (e.g., from $E_{0}\left(t_{j}\right)$ to $\left.\left.E_{0}\right|_{j}\right)$. Thus

$$
\begin{aligned}
& \int_{t_{j-1}}^{t_{j}} E_{1}\left(t_{i}-t^{\prime}\right) E_{0}\left(t^{\prime}\right) \mathrm{d} t^{\prime}= \\
& \frac{1}{4}\left(\left.E_{1}\right|_{i-j+1}+\left.E_{1}\right|_{i-j}\right)\left(\left.E_{0}\right|_{j-1}+\left.E_{0}\right|_{j}\right) \Delta t .
\end{aligned}
$$

Equation (B2) becomes Eq. (B6):

$$
\left.E_{2}\right|_{i}=\sum_{j=1}^{i} \frac{\Delta t}{4}\left(\left.E_{1}\right|_{i-j+1}+\left.E_{1}\right|_{i-j}\right)\left(\left.E_{0}\right|_{j-1}+\left.E_{0}\right|_{j}\right),
$$

where $i$ starts at 1 as $\left.E_{2}\right|_{0}=\left.E_{1}\right|_{0}=\left.E_{0}\right|_{0}=0$ (except for RTD of an ideal CSTR). Again, $E_{2}$ and $E_{1}$ are known by measurements, and $E_{0}$ is the unknown to be solved. Let $\boldsymbol{x}$ be $\left[\left.E_{0}\right|_{1},\left.E_{0}\right|_{2}, \ldots,\left.E_{0}\right|_{n}\right]$, where $n$ is an integer sufficiently large beyond which $E_{0}$ is considered to have converged to zero. Let

$$
\begin{aligned}
& a_{i, j}=\frac{\Delta t}{4}\left(\left.E_{1}\right|_{i-j+1}+\left.E_{1}\right|_{i-j}\right) \\
& \left.E_{2}\right|_{1}-\left.a_{1,1} E_{0}\right|_{0}=\left.a_{1,1} E_{0}\right|_{1} \\
& \left.E_{2}\right|_{2}-\left.a_{2,1} E_{0}\right|_{0}=\left.\left(a_{2,1}+a_{2,2}\right) E_{0}\right|_{1}+\left.a_{2,2} E_{0}\right|_{2} \\
& \left.E_{2}\right|_{3}-\left.a_{3,1} E_{0}\right|_{0}= \\
& \left.\left(a_{3,1}+a_{3,2}\right) E_{0}\right|_{1}+\left.\left(a_{3,2}+a_{3,3}\right) E_{0}\right|_{2}+\left.a_{3,3} E_{0}\right|_{3} \\
& \ldots
\end{aligned}
$$

Therefore, define the coefficient matrix $\mathbf{A}$ in Eq. (B8), where

$$
\mathbf{A}_{i, j}=\left\{\begin{array}{cl}
a_{i, i} & \text { if } j=i \\
a_{i, j}+a_{i, j+1} & \text { if } j<i \\
0 & \text { if } j>i
\end{array}\right.
$$

and define the vector $\boldsymbol{b}$ in Eq. (B9) where

$\boldsymbol{b}_{i}=\left.E_{2}\right|_{i}-\left.a_{i, 1} E_{0}\right|_{0}$.

In this way, the integral Eq. (B1) is converted to a linear algebra problem in Eq. (B10):

$\mathbf{A} x=b$.

Therefore, $E_{0}$ can be obtained by solving

$\boldsymbol{x}=\mathbf{A}^{-1} \boldsymbol{b}$.

This is called "direct deconvolution", which requires taking inverse of the coefficient matrix A. However, in some cases $\mathbf{A}$ is ill conditioned and the numerical inversion method like "inv(A)" in MATLAB does not converge. This nonideality results primarily from measurement uncertainties. Thus, instead of directly solving Eq. (B10), it is proposed in this work to first assume a reasonable function form for $\boldsymbol{x}$, e.g., the tanks-in-series (TIS) model, and then iteratively update the model parameters to minimize the residual of Eq. (B10). This "indirect deconvolution" method always yields a stable and accurate solution of $E_{0}$, the accuracy being judged by comparing $\boldsymbol{b}$ and $\boldsymbol{b}^{\prime}=\mathbf{A} \boldsymbol{x}^{\prime}$, where $\boldsymbol{x}^{\prime}$ represents the converged solution. The validity of the indirect deconvolution depends on the reactor model being assumed. The TIS model is one of the two most used non-ideal reactor models (the other one is the axial dispersion model), which has proven to work well for the PAM reactor under investigation. The model parameter $N$ (the number of CSTRs) indicates the non-ideality of the reactor; i.e., the greater $N$ is than 1 , the more differently the reactor behaves from an ideal CSTR. The mathematical form of the TIS model can be found in Sect. 3.2. 


\section{The Supplement related to this article is available online at https://doi.org/10.5194/amt-11-1741-2018-supplement.}

Competing interests. The authors declare that they have no conflict of interest.

Acknowledgements. We would like to express appreciation for the valuable discussions with Jay Turner, James Ballard, Christopher Oxford, David Hagan, and Tim Lee at Washington University in St. Louis, and valuable correspondence with William Brune at the Pennsylvania State University and Andrew Lambe at Aerodyne Research, Inc. We would also like to thank ENGYS and Milorad Duduković's CREL resources, which provided the necessary computational power to run CFD. This work was partly funded by the National Science Foundation (NSF) CBET Award no. 1236865, and NSF CBET Award no. 1437933.

Edited by: Jonathan Abbatt

Reviewed by: two anonymous referees

\section{References}

Aris, R.: On the Dispersion of a Solute in a Fluid Flowing through a Tube, P. Roy. Soc. A-Math. Phy., 235, 67-77, https://doi.org/10.1098/rspa.1956.0065, 1956.

Bourne, J. R.: Mixing and the Selectivity of Chemical Reactions, Org. Process Res. Dev., 7, 471-508, https://doi.org/10.1021/op020074q, 2003.

Brune, W. H., Schwab, J. J., and Anderson, J. G.: Laser magnetic resonance, resonance fluorescence, resonance absorption studies of the reaction kinetics of $\mathrm{O}+\mathrm{OH} \rightarrow \mathrm{H}+\mathrm{O}_{2}$, $\mathrm{O}+\mathrm{HO}_{2} \rightarrow \mathrm{OH}+\mathrm{O}_{2}, \mathrm{~N}+\mathrm{OH} \rightarrow \mathrm{H}+\mathrm{NO}, \mathrm{N}+\mathrm{HO}_{2} \rightarrow$ products at $300 \mathrm{~K}$ between 1 and 5 torr, J. Phys. Chem., 87, 45034514, https://doi.org/10.1021/j100245a034, 1983.

Bruns, E. A., El Haddad, I., Keller, A., Klein, F., Kumar, N. K., Pieber, S. M., Corbin, J. C., Slowik, J. G., Brune, W. H., Baltensperger, U., and Prévôt, A. S. H.: Inter-comparison of laboratory smog chamber and flow reactor systems on organic aerosol yield and composition, Atmos. Meas. Tech., 8, 23152332, https://doi.org/10.5194/amt-8-2315-2015, 2015.

Canagaratna, M. R., Jayne, J. T., Jimenez, J. L., Allan, J. D., Alfarra, M. R., Zhang, Q., Onasch, T. B., Drewnick, F., Coe, H., Middlebrook, A., Delia, A., Williams, L. R., Trimborn, A. M., Northway, M. J., DeCarlo, P. F., Kolb, C. E., Davidovits, P., and Worsnop, D. R.: Chemical and microphysical characterization of ambient aerosols with the aerodyne aerosol mass spectrometer, Mass Spectrom. Rev., 26, 185-222, https://doi.org/10.1002/mas.20115, 2007.

Cazorla, M. and Brune, W. H.: Measurement of Ozone Production Sensor, Atmos. Meas. Tech., 3, 545-555, https://doi.org/10.5194/amt-3-545-2010, 2010

Chhabra, P. S., Lambe, A. T., Canagaratna, M. R., Stark, H., Jayne, J. T., Onasch, T. B., Davidovits, P., Kimmel, J. R., and Worsnop, D. R.: Application of high-resolution time-of-flight chemical ionization mass spectrometry measurements to estimate volatility distributions of a-pinene and naphthalene oxidation products, Atmos. Meas. Tech., 8, 1-18, https://doi.org/10.5194/amt-8-12015, 2015.

Claeys, M.: Formation of Secondary Organic Aerosols Through Photooxidation of Isoprene, Science, 303, 1173-1176, https://doi.org/10.1126/science.1092805, 2004.

Crounse, J. D., McKinney, K. A., Kwan, A. J., and Wennberg, P. O.: Measurement of Gas-Phase Hydroperoxides by Chemical Ionization Mass Spectrometry, Anal. Chem., 78, 6726-6732, https://doi.org/10.1021/ac0604235, 2006.

Crump, J. G. and Seinfeld, J. H.: Aerosol behavior in the continuous stirred tank reactor, AIChE J., 26, 610-616, https://doi.org/10.1002/aic.690260412, 1980.

Crump, J. G., Flagan, R. C., and Seinfeld, J. H.: Particle Wall Loss Rates in Vessels, Aerosol Sci. Technol., 2, 303-309, https://doi.org/10.1080/02786828308958636, 1982.

Danckwerts, P. V.: Continuous flow systems, Chem. Eng. Sci., 2, 1-13, https://doi.org/10.1016/0009-2509(53)80001-1, 1953.

Deckwer, W.-D.: Non-isobaric bubble columns with variable gas velocity, Chem. Eng. Sci., 31, 309-317, https://doi.org/10.1016/0009-2509(76)85076-2, 1976.

de Gouw, J. and Warneke, C.: Measurements of volatile organic compounds in the earth's atmosphere using proton-transferreaction mass spectrometry, Mass Spectrom. Rev., 26, 223-257, https://doi.org/10.1002/mas.20119, 2007.

Ezell, M. J., Johnson, S. N., Yu, Y., Perraud, V., Bruns, E. A., Alexander, M. L., Zelenyuk, A., Dabdub, D., and Finlayson-Pitts, B. J.: A New Aerosol Flow System for Photochemical and Thermal Studies of Tropospheric Aerosols, Aerosol Sci. Technol., 44 329-338, https://doi.org/10.1080/02786821003639700, 2010.

Fogler, H. S.: Elements of chemical reaction engineering, 4th edn., Prentice Hall PTR, Upper Saddle River, NJ, 2006.

George, I. J. and Abbatt, J. P. D.: Chemical evolution of secondary organic aerosol from $\mathrm{OH}$-initiated heterogeneous oxidation, Atmos. Chem. Phys., 10, 5551-5563, https://doi.org/10.5194/acp10-5551-2010, 2010.

George, I. J., Vlasenko, A., Slowik, J. G., Broekhuizen, K., and Abbatt, J. P. D.: Heterogeneous oxidation of saturated organic aerosols by hydroxyl radicals: uptake kinetics, condensed-phase products, and particle size change, Atmos. Chem. Phys., 7, 41874201, https://doi.org/10.5194/acp-7-4187-2007, 2007.

Haagen-Smit, A. J.: Chemistry and Physiology of Los Angeles Smog, Ind. Eng. Chem., 44, 1342-1346, https://doi.org/10.1021/ie50510a045, 1952.

Haagen-Smit, A. J.: Photochemistry and Smog, Japca. J. Air Waste Ma., 13, 444-454, https://doi.org/10.1080/00022470.1963.10468205, 1963.

Haagen-Smit, A. J.: A Lesson from the Smog Capital of the World, P. Natl. Acad. Sci. USA, 67, 887-897, https://doi.org/10.1073/pnas.67.2.887, 1970.

Hamed, M.: Hydrodynamics, Mixing, and Mass Transfer in Bubble Columns with Internals, PhD, Washington University, Saint Louis, 2012.

Han, L.: Hydrodynamics, back-mixing, and mass transfer in a slurry bubble column reactor for Fischer-Tropsch alternative fuels, DSc, Washington University, Saint Louis, 2007.

Hansel, A., Jordan, A., Holzinger, R., Prazeller, P., Vogel, W., and Lindinger, W.: Proton transfer reaction mass spectrome- 
try: on-line trace gas analysis at the ppb level, Int. J. Mass Spectrom., 149-150, 609-619, https://doi.org/10.1016/01681176(95)04294-U, 1995.

Howard, C. J.: Kinetic measurements using flow tubes, J. Phys. Chem., 83, 3-9, https://doi.org/10.1021/j100464a001, 1979.

Huang, Y., Coggon, M. M., Zhao, R., Lignell, H., Bauer, M. U., Flagan, R. C., and Seinfeld, J. H.: The Caltech Photooxidation Flow Tube reactor: design, fluid dynamics and characterization, Atmos. Meas. Tech., 10, 839-867, https://doi.org/10.5194/amt10-839-2017, 2017.

Jayne, J. T., Leard, D. C., Zhang, X., Davidovits, P., Smith, K. A., Kolb, C. E., and Worsnop, D. R.: Development of an Aerosol Mass Spectrometer for Size and Composition Analysis of Submicron Particles, Aerosol Sci. Technol., 33, 49-70, https://doi.org/10.1080/027868200410840, 2000.

Kamens, R. M., Gery, M. W., Jeffries, H. E., Jackson, M., and Cole, E. I.: Ozone-isoprene reactions: Product formation and aerosol potential, Int. J. Chem. Kinet., 14, 955-975, https://doi.org/10.1002/kin.550140902, 1982.

Kang, E., Root, M. J., Toohey, D. W., and Brune, W. H.: Introducing the concept of Potential Aerosol Mass (PAM), Atmos. Chem. Phys., 7, 5727-5744, https://doi.org/10.5194/acp-7-5727-2007, 2007.

Kang, E., Toohey, D. W., and Brune, W. H.: Dependence of SOA oxidation on organic aerosol mass concentration and $\mathrm{OH}$ exposure: experimental PAM chamber studies, Atmos. Chem. Phys., 11, 1837-1852, https://doi.org/10.5194/acp-11-1837-2011, 2011.

Katrib, Y., Biskos, G., Buseck, P. R., Davidovits, P., Jayne, J. T., Mochida, M., Wise, M. E., Worsnop, D. R., and Martin, S. T.: Ozonolysis of Mixed Oleic-Acid/Stearic-Acid Particles: Reaction Kinetics and Chemical Morphology, J. Phys. Chem. A, 109, 10910-10919, https://doi.org/10.1021/jp054714d, 2005.

Keller, A. and Burtscher, H.: A continuous photo-oxidation flow reactor for a defined measurement of the SOA formation potential of wood burning emissions, J. Aerosol Sci., 49, 9-20, https://doi.org/10.1016/j.jaerosci.2012.02.007, 2012.

Kessler, S. H., Smith, J. D., Che, D. L., Worsnop, D. R., Wilson, K. R., and Kroll, J. H.: Chemical Sinks of Organic Aerosol: Kinetics and Products of the Heterogeneous Oxidation of Erythritol and Levoglucosan, Environ. Sci. Technol., 44, 7005-7010, https://doi.org/10.1021/es101465m, 2010.

Kessler, S. H., Nah, T., Daumit, K. E., Smith, J. D., Leone, S. R., Kolb, C. E., Worsnop, D. R., Wilson, K. R., and Kroll, J. H.: OH-Initiated Heterogeneous Aging of Highly Oxidized Organic Aerosol, J. Phys. Chem. A, 116, 6358-6365, https://doi.org/10.1021/jp212131m, 2012.

Keyser, L. F.: Absolute rate constant of the reaction $\mathrm{OH}+\mathrm{H}_{2} \mathrm{O}_{2} \rightarrow \mathrm{HO}_{2}+\mathrm{H}_{2} \mathrm{O}$ from 245 to $423 \mathrm{~K}$, J. Phys. Chem., 84, 1659-1663, https://doi.org/10.1021/j100450a001, 1980.

Keyser, L. F.: High-pressure flow kinetics. A study of the hydroxyl + hydrogen chloride reaction from 2 to 100 torr, J. Phys. Chem., 88, 4750-4758, https://doi.org/10.1021/j150664a061, 1984.

Knopf, D. A., Anthony, L. M., and Bertram, A. K.: Reactive Uptake of $\mathrm{O}_{3}$ by Multicomponent and Multiphase Mixtures Containing Oleic Acid, J. Phys. Chem. A, 109, 5579-5589, https://doi.org/10.1021/jp0512513, 2005.
Kroll, J. H. and Seinfeld, J. H.: Chemistry of secondary organic aerosol: Formation and evolution of low-volatility organics in the atmosphere, Atmos. Environ., 42, 3593-3624, https://doi.org/10.1016/j.atmosenv.2008.01.003, 2008.

Kroll, J. H., Ng, N. L., Murphy, S. M., Flagan, R. C., and Seinfeld, J. H.: Secondary Organic Aerosol Formation from Isoprene Photooxidation, Environ. Sci. Technol., 40, 1869-1877, https://doi.org/10.1021/es0524301, 2006.

Kroll, J. H., Smith, J. D., Worsnop, D. R., and Wilson, K. R.: Characterisation of lightly oxidised organic aerosol formed from the photochemical aging of diesel exhaust particles, Environ. Chem., 9, 211-220, https://doi.org/10.1071/EN11162, 2012.

Lamb, J. J., Molina, L. T., Smith, C. A., and Molina, M. J.: Rate constant of the hydroxy radical + hydrogen peroxide .fwdarw. hydroperoxo radical + water reaction, J. Phys. Chem., 87, 44674470, https://doi.org/10.1021/j100245a028, 1983.

Lambe, A., Massoli, P., Zhang, X., Canagaratna, M., Nowak, J., Daube, C., Yan, C., Nie, W., Onasch, T., Jayne, J., Kolb, C., Davidovits, P., Worsnop, D., and Brune, W.: Controlled nitric oxide production via $\mathrm{O}\left({ }^{1} \mathrm{D}\right)+\mathrm{N}_{2} \mathrm{O}$ reactions for use in oxidation flow reactor studies, Atmos. Meas. Tech., 10, 2283-2298, https://doi.org/10.5194/amt-10-2283-2017, 2017.

Lambe, A. T., Ahern, A. T., Williams, L. R., Slowik, J. G., Wong, J. P. S., Abbatt, J. P. D., Brune, W. H., Ng, N. L., Wright, J. P., Croasdale, D. R., Worsnop, D. R., Davidovits, P., and Onasch, T. B.: Characterization of aerosol photooxidation flow reactors: heterogeneous oxidation, secondary organic aerosol formation and cloud condensation nuclei activity measurements, Atmos. Meas. Tech., 4, 445-461, https://doi.org/10.5194/amt-4445-2011, 2011a.

Lambe, A. T., Onasch, T. B., Massoli, P., Croasdale, D. R., Wright, J. P., Ahern, A. T., Williams, L. R., Worsnop, D. R., Brune, W. H., and Davidovits, P.: Laboratory studies of the chemical composition and cloud condensation nuclei ( $\mathrm{CCN})$ activity of secondary organic aerosol (SOA) and oxidized primary organic aerosol (OPOA), Atmos. Chem. Phys., 11, 8913-8928, https://doi.org/10.5194/acp-11-8913-2011, 2011 b.

Lambe, A. T., Onasch, T. B., Croasdale, D. R., Wright, J. P., Martin, A. T., Franklin, J. P., Massoli, P., Kroll, J. H., Canagaratna, M. R., Brune, W. H., Worsnop, D. R., and Davidovits, P.: Transitions from Functionalization to Fragmentation Reactions of Laboratory Secondary Organic Aerosol (SOA) Generated from the OH Oxidation of Alkane Precursors, Environ. Sci. Technol., 46, 5430-5437, https://doi.org/10.1021/es300274t, 2012.

Lambe, A. T., Cappa, C. D., Massoli, P., Onasch, T. B., Forestieri, S. D., Martin, A. T., Cummings, M. J., Croasdale, D. R., Brune, W. H., Worsnop, D. R., and Davidovits, P.: Relationship between Oxidation Level and Optical Properties of Secondary Organic Aerosol, Environ. Sci. Technol., 47, 6349-6357, https://doi.org/10.1021/es401043j, 2013.

Lambe, A. T., Chhabra, P. S., Onasch, T. B., Brune, W. H., Hunter, J. F., Kroll, J. H., Cummings, M. J., Brogan, J. F., Parmar, Y., Worsnop, D. R., Kolb, C. E., and Davidovits, P.: Effect of oxidant concentration, exposure time, and seed particles on secondary organic aerosol chemical composition and yield, Atmos. Chem. Phys., 15, 3063-3075, https://doi.org/10.5194/acp15-3063-2015, 2015.

Leone, J. A., Flagan, R. C., Grosjean, D., and Seinfeld, J. H.: An outdoor smog chamber and modeling study of toluene- 
$\mathrm{NO}_{x}$ photooxidation, Int. J. Chem. Kinet., 17, 177-216, https://doi.org/10.1002/kin.550170206, 1985.

Levenspiel, O.: Chemical reaction engineering, 3rd edn., Wiley, New York, 1999.

Levenspiel, O.: The chemical reactor omnibook, OSU Book Stores, Corvallis, Or., 2002.

Li, R., Palm, B. B., Ortega, A. M., Hlywiak, J., Hu, W., Peng, Z., Day, D. A., Knote, C., Brune, W. H., de Gouw, J. A., and Jimenez, J. L.: Modeling the Radical Chemistry in an Oxidation Flow Reactor: Radical Formation and Recycling, Sensitivities, and the $\mathrm{OH}$ Exposure Estimation Equation, J. Phys. Chem. A, 119, 4418-4432, https://doi.org/10.1021/jp509534k, 2015.

Liu, P. F., Abdelmalki, N., Hung, H.-M., Wang, Y., Brune, W. H., and Martin, S. T.: Ultraviolet and visible complex refractive indices of secondary organic material produced by photooxidation of the aromatic compounds toluene and m-xylene, Atmos. Chem. Phys., 15, 1435-1446, https://doi.org/10.5194/acp15-1435-2015, 2015.

MacMullin, R. B. and Weber Jr., M.: The theory of short-circuiting in continuous-flow mixing vessels in series and the kinetics of chemical reactions in such systems, Trans. AIChE, 31, 409-458, 1935.

Massoli, P., Lambe, A. T., Ahern, A. T., Williams, L. R., Ehn, M., Mikkilä, J., Canagaratna, M. R., Brune, W. H., Onasch, T. B., Jayne, J. T., Petäjä, T., Kulmala, M., Laaksonen, A., Kolb, C. E., Davidovits, P., and Worsnop, D. R.: Relationship between aerosol oxidation level and hygroscopic properties of laboratory generated secondary organic aerosol (SOA) particles: HYGROSCOPICITY OF LABORATORY SOA, Geophys. Res. Lett., 37, L24801, https://doi.org/10.1029/2010GL045258, 2010.

McNeill, V. F., Yatavelli, R. L. N., Thornton, J. A., Stipe, C. B., and Landgrebe, O.: Heterogeneous $\mathrm{OH}$ oxidation of palmitic acid in single component and internally mixed aerosol particles: vaporization and the role of particle phase, Atmos. Chem. Phys., 8, 5465-5476, https://doi.org/10.5194/acp-8-5465-2008, 2008.

Mills, P. L. and Duduković, M. P.: Deconvolution of noisy tracer response data by a linear filtering method, AIChE J., 34, 17521756, https://doi.org/10.1002/aic.690341025, 1988.

Nozière, B., Barnes, I., and Becker, K.-H.: Product study and mechanisms of the reactions of $\alpha$-pinene and of pinonaldehyde with $\mathrm{OH}$ radicals, J. Geophys. Res., 104, 23645-23656, https://doi.org/10.1029/1999JD900778, 1999.

Ortega, A. M., Day, D. A., Cubison, M. J., Brune, W. H., Bon, D., de Gouw, J. A., and Jimenez, J. L.: Secondary organic aerosol formation and primary organic aerosol oxidation from biomassburning smoke in a flow reactor during FLAME-3, Atmos. Chem. Phys., 13, 11551-11571, https://doi.org/10.5194/acp-1311551-2013, 2013.

Ortega, A. M., Hayes, P. L., Peng, Z., Palm, B. B., Hu, W., Day, D. A., Li, R., Cubison, M. J., Brune, W. H., Graus, M., Warneke, C., Gilman, J. B., Kuster, W. C., de Gouw, J., GutiérrezMontes, C., and Jimenez, J. L.: Real-time measurements of secondary organic aerosol formation and aging from ambient air in an oxidation flow reactor in the Los Angeles area, Atmos. Chem. Phys., 16, 7411-7433, https://doi.org/10.5194/acp16-7411-2016, 2016.

Palm, B. B., Campuzano-Jost, P., Day, D. A., Ortega, A. M., Fry, J. L., Brown, S. S., Zarzana, K. J., Dube, W., Wagner, N. L., Draper, D. C., Kaser, L., Jud, W., Karl, T., Hansel, A., Gutiérrez-
Montes, C., and Jimenez, J. L.: Secondary organic aerosol formation from in situ $\mathrm{OH}, \mathrm{O}_{3}$, and $\mathrm{NO}_{3}$ oxidation of ambient forest air in an oxidation flow reactor, Atmos. Chem. Phys., 17, 53315354, https://doi.org/10.5194/acp-17-5331-2017, 2017.

Palm, B. B., de Sá, S. S., Day, D. A., Campuzano-Jost, P., Hu, W., Seco, R., Sjostedt, S. J., Park, J.-H., Guenther, A. B., Kim, S., Brito, J., Wurm, F., Artaxo, P., Thalman, R., Wang, J., Yee, L. D., Wernis, R., Isaacman-VanWertz, G., Goldstein, A. H., Liu, Y., Springston, S. R., Souza, R., Newburn, M. K., Alexander, M. L., Martin, S. T., and Jimenez, J. L.: Secondary organic aerosol formation from ambient air in an oxidation flow reactor in central Amazonia, Atmos. Chem. Phys., 18, 467-493, https://doi.org/10.5194/acp-18-467-2018, 2018.

Paulson, S. E., Pandis, S. N., Baltensperger, U., Seinfeld, J. H., Flagan, R. C., Palen, E. J., Allen, D. T., Schaffner, C., Giger, W., and Portmann, A.: Characterization of photochemical aerosols from biogenic hydrocarbons, J. Aerosol Sci., 21, S245-S248, https://doi.org/10.1016/0021-8502(90)90230-U, 1990.

Peng, Z. and Jimenez, J. L.: Modeling of the chemistry in oxidation flow reactors with high initial NO, Atmos. Chem. Phys., 17, 11991-12010, https://doi.org/10.5194/acp-17-11991-2017, 2017.

Peng, Z., Day, D. A., Stark, H., Li, R., Lee-Taylor, J., Palm, B. B., Brune, W. H., and Jimenez, J. L.: $\mathrm{HO}_{x}$ radical chemistry in oxidation flow reactors with low-pressure mercury lamps systematically examined by modeling, Atmos. Meas. Tech., 8, 4863-4890, https://doi.org/10.5194/amt-8-4863-2015, 2015.

Peng, Z., Day, D. A., Ortega, A. M., Palm, B. B., Hu, W., Stark, H., Li, R., Tsigaridis, K., Brune, W. H., and Jimenez, J. L.: Non$\mathrm{OH}$ chemistry in oxidation flow reactors for the study of atmospheric chemistry systematically examined by modeling, Atmos. Chem. Phys., 16, 4283-4305, https://doi.org/10.5194/acp16-4283-2016, 2016.

Peng, Z., Palm, B. B., Day, D. A., Talukdar, R. K., Hu, W., Lambe, A. T., Brune, W. H., and Jimenez, J. L.: Model Evaluation of New Techniques for Maintaining High-NO Conditions in Oxidation Flow Reactors for the Study of OH-Initiated Atmospheric Chemistry, ACS Earth Space Chem., 2, 72-86, https://doi.org/10.1021/acsearthspacechem.7b00070, 2017.

Pereira, K. L., Hamilton, J. F., Rickard, A. R., Bloss, W. J., Alam, M. S., Camredon, M., Ward, M. W., Wyche, K. P., Muñoz, A., Vera, T., Vázquez, M., Borrás, E., and Ródenas, M.: Insights into the Formation and Evolution of Individual Compounds in the Particulate Phase during Aromatic Photo-Oxidation, Environ. Sci. Technol., 49, 13168-13178, https://doi.org/10.1021/acs.est.5b03377, 2015.

Renbaum, L. H. and Smith, G. D.: Artifacts in measuring aerosol uptake kinetics: the roles of time, concentration and adsorption, Atmos. Chem. Phys., 11, 6881-6893, https://doi.org/10.5194/acp-11-6881-2011, 2011.

Rudich, Y., Donahue, N. M., and Mentel, T. F.: Aging of Organic Aerosol: Bridging the Gap Between Laboratory and Field Studies, Annu. Rev. Phys. Chem., 58, 321-352, https://doi.org/10.1146/annurev.physchem.58.032806.104432, 2007.

Seinfeld, J. H. and Pandis, S. N.: Atmospheric chemistry and physics: from air pollution to climate change, 2nd edn., J. Wiley, Hoboken, NJ, 2006. 
Simonen, P., Saukko, E., Karjalainen, P., Timonen, H., Bloss, M., Aakko-Saksa, P., Rönkkö, T., Keskinen, J., and Dal Maso, M.: A new oxidation flow reactor for measuring secondary aerosol formation of rapidly changing emission sources, Atmos. Meas. Tech., 10, 1519-1537, https://doi.org/10.5194/amt10-1519-2017, 2017.

Slowik, J. G., Wong, J. P. S., and Abbatt, J. P. D.: Realtime, controlled $\mathrm{OH}$-initiated oxidation of biogenic secondary organic aerosol, Atmos. Chem. Phys., 12, 9775-9790, https://doi.org/10.5194/acp-12-9775-2012, 2012.

Smith, J. D., Kroll, J. H., Cappa, C. D., Che, D. L., Liu, C. L., Ahmed, M., Leone, S. R., Worsnop, D. R., and Wilson, K. R.: The heterogeneous reaction of hydroxyl radicals with submicron squalane particles: a model system for understanding the oxidative aging of ambient aerosols, Atmos. Chem. Phys., 9, 3209-3222, https://doi.org/10.5194/acp-9-3209-2009, 2009.

Sun, Y.: Study on the Internal Effect of Inhibiting Gas and Solid Back-Mixing in Fluidized Beds, Masters thesis, Tsinghua University, Beijing, 2010.

Taylor, G.: Dispersion of Soluble Matter in Solvent Flowing Slowly through a Tube, P. Roy. Soc. A-Math. Phy., 219, 186-203, https://doi.org/10.1098/rspa.1953.0139, 1953.

Taylor, G.: Conditions under Which Dispersion of a Solute in a Stream of Solvent can be Used to Measure Molecular Diffusion, P. Roy. Soc. A-Math. Phy., 225, 473-477, https://doi.org/10.1098/rspa.1954.0216, 1954a.

Taylor, G. I.: Diffusion and Mass Transport in Tubes, P. Phys. Soc. Lond. B, 67, 857-869, https://doi.org/10.1088/03701301/67/12/301, 1954b.
Turpin, B. J., Saxena, P., and Andrews, E.: Measuring and simulating particulate organics in the atmosphere: problems and prospects, Atmos. Environ., 34, 2983-3013, https://doi.org/10.1016/S1352-2310(99)00501-4, 2000.

Villermaux, J.: Macro and Micromixing Phenomena in Chemical Reactors, in Chemical Reactor Design and Technology, edited by: Lasa, H. I., Springer Netherlands, Dordrecht, 191244, available at: http://www.springerlink.com/index/10.1007/ 978-94-009-4400-8_6 (last access: 11 December 2015), 1986.

Volkamer, R., Platt, U., and Wirtz, K.: Primary and Secondary Glyoxal Formation from Aromatics: Experimental Evidence for the Bicycloalkyl-Radical Pathway from Benzene, Toluene, and p-Xylene, J. Phys. Chem. A, 105, 7865-7874, https://doi.org/10.1021/jp010152w, 2001.

Went, F. W.: Blue Hazes in the Atmosphere, Nature, 187, 641-643, https://doi.org/10.1038/187641a0, 1960.

Williams, B. J., Goldstein, A. H., Kreisberg, N. M., and Hering, S. V.: An In-Situ Instrument for Speciated Organic Composition of Atmospheric Aerosols: $\mathrm{T}$ hermal Desorption A erosol G C/MS-FID (TAG), Aerosol Sci. Technol., 40, 627-638, https://doi.org/10.1080/02786820600754631, 2006.

Zhao, Y., Kreisberg, N. M., Worton, D. R., Teng, A. P., Hering, S. V., and Goldstein, A. H.: Development of an In Situ Thermal Desorption Gas Chromatography Instrument for Quantifying Atmospheric Semi-Volatile Organic Compounds, Aerosol Sci. Technol., 47, 258-266, https://doi.org/10.1080/02786826.2012.747673, 2013.

Zwietering, T. N.: The degree of mixing in continuous flow systems, Chem. Eng. Sci., 11, 1-15, https://doi.org/10.1016/00092509(59)80068-3, 1959. 